\title{
Markers of Oxidative Stress and Antioxidant Status in the Plasma, Urine and Saliva of Healthy Mice
}

\author{
M. GYURÁSZOVÁ ${ }^{1}$, A. KOVALČÍKOVÁ ${ }^{1}$, K. JANŠÁKOVÁ ${ }^{2}$, K. ŠEBEKOVÁ ${ }^{1}$, \\ P. CELEC ${ }^{1,3,4}$, L. TÓTHOVÁ ${ }^{1}$
}

${ }^{1}$ Institute of Molecular Biomedicine, Faculty of Medicine, Comenius University, Bratislava, Slovakia, ${ }^{2}$ Institute of Physiology, Faculty of Medicine, Comenius University, Bratislava, Slovakia, ${ }^{3}$ Institute of Pathophysiology, Faculty of Medicine, Comenius University, Bratislava, Slovakia, ${ }^{4}$ Department of Molecular Biology, Faculty of Natural Sciences, Comenius University, Bratislava, Slovakia

Received January 21, 2018

Accepted June 6, 2018

On-line September 11, 2018

\section{Summary}

Oxidative stress markers are usually measured in plasma, a stable environment for biomarkers. Blood collection is invasive, but the use of alternative biofluids is limited, due to high variability. In this study, we aimed to establish reference values for oxidative stress markers in plasma, urine and saliva of adult, healthy mice and to identify some sources of variability. Samples were obtained from 41 female and 37 male adult, healthy mice of the CD-1 strain, aged 95-480 days, weighing 21-55 grams. Reference ranges of TBARS (thiobarbituric acid reactive substances), AOPP (advanced oxidation protein products), fructosamine, GSH/GSSG (reduced and oxidized glutathione) ratio, TAC (total antioxidant capacity), and FRAP (ferric reducing antioxidant power) were measured in plasma and urine, and TBARS, GSH/GSSG ratio, TAC and FRAP in saliva, using standard spectrophotometric and fluorometric methods. Salivary GSH/GSSG and urinary AOPP were higher in females. Urinary fructosamine, GSH/GSSG and FRAP were higher in males. Urinary TAC and FRAP negatively correlated with age, and urinary GSH/GSSG positively correlated with weight. We determined that urine and saliva can be obtained non-invasively from mice, in sufficient amounts for reliable oxidative status assessment. Further studies are needed to uncover whether these biofluids reflect systemic oxidative status in diseases.

\section{Key words}

Antioxidant status • Sex difference • Biomarker • Saliva • Urine

\section{Corresponding author}

L'. Tóthová, Institute of Molecular Biomedicine, Faculty of Medicine, Comenius University, Sasinkova 4, 81108 Bratislava, Slovakia. E-mail: tothova.lubomira@gmail.com

\section{Introduction}

Reactive oxygen species (ROS) play an important role in the defense mechanisms and in the destruction of damaged cells, they can act as intra- and extracellular messengers and contribute to homeostasis. However, excessive production of ROS may have detrimental effects on the organism, so endogenous and exogenous antioxidant systems help to maintain balance. An imbalance between the production of ROS and their elimination by antioxidants leads to oxidative stress (Sies 1997). Oxidative stress affects all macromolecules, impairs organ functions, and is involved in the pathogenesis of various diseases. Markers of oxidative stress and antioxidant status can be measured in plasma or in tissues in order to evaluate or monitor the disease state and progression (Valko et al. 2007).

It is important to note that oxidative stress is a phenomenon that is difficult to characterize. The great diversity in oxidative stress between diseases and conditions has to be taken into account when selecting the appropriate biomarkers (Frijhoff et al. 2015). Our study focused on some of the most commonly used. Lipid peroxidation is mainly assessed by measuring 
malondialdehyde, and protein oxidation by measuring advanced oxidation protein products (AOPP) (CapeillèreBlandin et al. 2004). The ratio of reduced and oxidized glutathione (GSH/GSSG) is used as a general marker of oxidative stress (Zitka et al. 2012). To avoid the need for measuring several individual antioxidants, total antioxidant capacity (TAC) or ferric reducing antioxidant power (FRAP) is analyzed (Benzie and Strain 1996, Erel 2004). Carbonyl stress is an irreversible form of non-enzymatic glycation (Bargnoux et al. 2009). The determination of fructosamine, an Amadori product, is used to assess non-enzymatic glycation (Kishabongo et al. 2015).

Oxidative stress markers are usually measured in plasma or serum, as both represent a relatively stable environment for systemic biomarkers. However, blood collection represents a significant stress to patients. Thus, other biofluids are being tested as alternatives to plasma. These biofluids should be easier to obtain and in sufficient amounts (Čolak 2008). Urine has the potential to be an alternative biofluid for oxidative stress assessment, as its collection is less invasive and requires less effort, equipment and trained staff than blood collection. Besides, urine can be obtained in large volumes repeatedly during the day. Also, urine has been argued to be a better environment for oxidative stress measurement than plasma, as it has a lower organic and inorganic metal content, and lower levels of ROS promoters, therefore, urine is less liable to artificial increase of oxidative stress markers during sampling and storage (Il'yasova et al. 2012). Saliva collection is also inexpensive, easy, fast, and non-invasive. During the collection of both of these biofluids, there is no risk of vessel injury or infection, and they could be collected without the help of a nurse or a doctor. Saliva collection is preferred by non-compliant patients, such as children or elderly people. Saliva and urine are also suitable for home use, since they are easy to store and transport (Lee and Wong 2009).

Despite the possibility to analyze a wide range of markers in urine or saliva, their use in clinical practice is still limited. The main problem is the high intra- and inter-individual variability of the measured markers (Behuliak et al. 2009, Kamodyová et al. 2013, Tóthová et al. 2015). The sources of this variability remain largely unknown. Therefore, it is necessary to identify the underlying factors of technical and biological variability. Because it is difficult to eliminate bias in human studies, research in healthy animals and animal models of various diseases is the only way to study factors that might influence the variability of urinary and salivary biomarkers. Based on studies conducted in humans, an effect of gender on oxidative stress has been proposed, as females might be more protected against oxidative stress, by the antioxidant effects of estrogens (Bloomer and Fisher-Wellman 2008). It has also been postulated that systemic oxidative stress can play a role in the aging process, and that oxidative stress increases with bodyweight and can be induced by obesity (Harman 1956, Chrysohoou et al. 2007, Fernández-Sánchez et al. 2011, Serra et al. 2013, Savini et al. 2013). Whether this is true for experimental animals and their body fluids, is unknown.

The wide use of oxidative stress markers calls for standardization and the determination of whether these markers correlate between individual body fluids. Oxidative stress markers measured in various body fluids might reflect the local oxidative status, rather than the systemic, at least in healthy animals. The aim of this study was to establish reference values for oxidative status markers in plasma, urine and saliva of adult healthy mice of both sexes and to identify the underlying factors of high inter-individual variability.

\section{Materials and Methods}

\section{Animals}

Healthy female $(n=41)$ and male $(n=37)$ adult mice of the CD-1 strain (Anlab, Prague, Czech Republic) were used in this experiment. The age of the mice was between 95-480 days (Supplementary Fig. S4) and their weight between $21-55 \mathrm{~g}$. The animals were housed in standard cages with wood bedding, and had free access to water and standard rodent pellet chow Ssniff R/M-H (Anlab, Prague, Czech Republic). All mice were kept in a room with a $12 / 12 \mathrm{~h}$ light/dark cycle. Experiments were performed in full compliance with the EU Guidelines for Scientific Experimentation on Animals, and were approved by the Ethics committee of the Institute of Molecular Biomedicine, Slovakia (010/2016/SKP1012).

\section{Sample collection}

To obtain plasma samples, mice were anesthetized using the isoflurane drop-method, by placing the mice briefly in a closed jar with a cotton pad wetted with several drops of non-diluted isoflurane. Blood was collected from the retro-orbital plexus into two $500 \mu \mathrm{l}$ EDTA coated blood collection tubes (up to $250 \mu 1$ of 
blood into each tube) (Sarstedt, Numbrecht, Germany). Plasma was obtained by centrifugation $(2,000 \mathrm{~g}$ for $7 \mathrm{~min}$ ), plasma samples were stored at $-20{ }^{\circ} \mathrm{C}$. Urine samples were collected during $4 \mathrm{~h}$ of fasting in metabolic cages, to the volume of $800 \mu \mathrm{l}$ on average, and stored at $-20{ }^{\circ} \mathrm{C}$ prior to analysis. For saliva collection, mice were anesthetized with intraperitoneal injection of ketamine (100 mg/kg, Richter Pharma AG, Wels, Austria) and xylazine (10 mg/kg, Ecuphar N. V., Oostkamp, Belgium). Salivation was induced using pilocarpine $(0.5 \mu \mathrm{g} / \mathrm{kg}$, Unimed Pharma, Bratislava, Slovakia). Saliva samples were collected for $30 \mathrm{~min}$, to the volume of $400 \mu \mathrm{l}$, approximately, and stored at $-20^{\circ} \mathrm{C}$ prior to analysis.

\section{Biochemical analysis}

Markers of oxidative stress and antioxidant status were assessed in plasma, urine and saliva samples. Measurements were performed on a TecanSaphire II Instrument (Grödig, Austria), and the chemicals used in the analyses were purchased from Sigma Aldrich (Steinheim, Germany).

Thiobarbituric acid reactive substances (TBARS) were measured as described previously (Tóthová et al. 2013). Briefly, $20 \mu 1$ of samples or standards (1,1,3,3-tetraethoxypropane) were mixed with $30 \mu \mathrm{l}$ of distilled water, $20 \mu \mathrm{l}$ of $0.67 \%$ thiobartituric acid and $20 \mu \mathrm{l}$ of glacial acetic acid. The plates were shortly mixed and incubated for $45 \mathrm{~min}$ at $95^{\circ} \mathrm{C}$. Afterwards, $100 \mu \mathrm{l}$ of n-butanol were added into the samples and plates were centrifuged $(2,000 \mathrm{~g} / 10 \mathrm{~min} /$ $4{ }^{\circ} \mathrm{C}$ ). Seventy $\mu \mathrm{l}$ of the upper phase were transferred into a new microtiter plate and fluorescence was measured at $\lambda_{\mathrm{ex}}=515 \mathrm{~nm}$ and $\lambda_{\mathrm{em}}=535 \mathrm{~nm}$.

AOPP were used as a marker of protein damage. For the analysis, $200 \mu \mathrm{l}$ of samples and standards (chloramine $\mathrm{T}$ mixed with potassium iodide) were mixed with $20 \mu \mathrm{l}$ of glacial acetic acid. After mixing for $2 \mathrm{~min}$, absorbance was measured at $340 \mathrm{~nm}$ (Tóthová et al. 2013).

Fructosamine was used as a marker of advanced glycation. Twenty $\mu \mathrm{l}$ of the samples and standards (16 mmol/1 1-deoxy-morpholino-D-fructose) were mixed with $100 \mu \mathrm{l}$ of $0.25 \mathrm{mmol} / 1$ nitro blue tetrazolium containing $1 \mathrm{mmol} / \mathrm{l}$ nitro blue tetrazolium and $0.1 \mathrm{~mol} / \mathrm{l}$ sodium carbonate buffer $(\mathrm{pH}=10.35)$. Samples were incubated at $37^{\circ} \mathrm{C}$ for $15 \mathrm{~min}$. Absorbance was measured at $530 \mathrm{~nm}$ (Tóthová et al. 2013).

For the GSH/GSSG ratio, GSH was measured by mixing $10 \mu \mathrm{l}$ of the samples with $10 \mu \mathrm{l}$ of the
O-phtalaldehyde solution $(1 \mathrm{mg} / \mathrm{ml})$ and $180 \mu \mathrm{l}$ of the phosphate buffer solution $(100 \mathrm{mmol} / \mathrm{l}$ with $2.5 \mathrm{mM}$ EDTA- $\mathrm{Na}_{2}$ ). The mixture was then incubated $15 \mathrm{~min}$ at room temperature. Afterwards, specific fluorescence at $\lambda_{\mathrm{ex}}=350 \mathrm{~nm}, \lambda_{\mathrm{em}}=460 \mathrm{~nm}$ was measured. GSSG was measured by mixing $25 \mu \mathrm{l}$ of the samples and $10 \mu \mathrm{l}$ of N-ethylmaleimide $(5 \mathrm{~g} / \mathrm{ml})$ and incubation for $40 \mathrm{~min}$ at room temperature. Ten $\mu 1$ of the mixture were transferred to new microtiter plate with addition of $10 \mu \mathrm{l}$ of the O-phtalaldehyde $(1 \mathrm{mg} / \mathrm{ml})$ and $180 \mu \mathrm{l}$ of $\mathrm{NaOH}$ $(0.1 \mathrm{~mol} / \mathrm{l})$. After $15 \mathrm{~min}$ incubation at room temperature, specific fluorescence was measured at $\lambda_{\mathrm{ex}}=350 \mathrm{~nm}$, $\lambda_{\mathrm{em}}=460 \mathrm{~nm}$. GSH values were divided with GSSG values to assess their ratio (Tóthová et al. 2013).

For the measurement of TAC, $20 \mu \mathrm{l}$ of samples were mixed with acetate buffer $(\mathrm{pH}=5.8)$. The initial absorbance was measured at $660 \mathrm{~nm}$ as blank. When ABTS solution (2.2'-azino-bis(3-ethylbenzthiazoline-6sulphonic acid with acetate buffer) was added, the absorbance $(660 \mathrm{~nm})$ was measured again. The blank absorbance values were subtracted from the values obtained by the second measurement (Tóthová et al. 2013).

FRAP was used as a marker of antioxidant status. Two hundred $\mu$ l of warmed $\left(37^{\circ} \mathrm{C}\right)$ FRAP reagent (containing acetate buffer, $\mathrm{pH}=3.6$; tripyridyl-s-triazine; $\mathrm{FeCl}_{3} * 6 \mathrm{H}_{2} \mathrm{O}$ and water) were pipetted into a microtiter plate. Absorbance was measured as blank. Afterwards, $20 \mu \mathrm{l}$ of samples and standards $\quad(100 \mathrm{mmol} / \mathrm{l}$ $\mathrm{FeSO}_{4} * 7 \mathrm{H}_{2} \mathrm{O}$ ) were added. Absorbance was measured again at $530 \mathrm{~nm}$. The blank absorbance values were subtracted from the values obtained by the second measurement (Tóthová et al. 2013).

Creatinine concentrations in the urine samples were measured using the spectrophotometric method by Jaffe (Askenazi et al. 2014). Ten $\mu$ of samples were mixed with mixture of $\mathrm{NaOH}$ and picric acid (ratio 5:1). After $6 \mathrm{~min}$, the absorbance was measured at $492 \mathrm{~nm}$.

For the measurement of proteins in plasma and urine, $10 \mu \mathrm{l}$ of the samples and standards (bovine serum albumin) were used. Afterwards, according to the manufacturer's instructions, $200 \mu \mathrm{l}$ of the working solution (bicinchoninic acid and copper sulphate, 49:1 ratio, respectively) were added. Samples were incubated at $37^{\circ} \mathrm{C}$ for $30 \mathrm{~min}$. After cooling the samples at room temperature, absorbance was measured at $562 \mathrm{~nm}$.

TBARS, fructosamine, TAC and FRAP were normalized to urinary creatinine in urine samples. AOPP 
were normalized to plasma proteins in plasma and urinary proteins in urine. To evaluate intra- and inter-assay variability, coefficient of variation (CV) was calculated. Limit of detection (LOD) was also determined for each assay type.

\section{Statistical analysis}

GraphPad Prism 5.0 (GraphPad Software, San Diego, CA, USA) was used for the statistical analyses. After testing for normality with the D'Agostino-Pearson omnibus test, data were analyzed with the Mann-Whitney $\mathrm{U}$ test. For the correlations, Spearman correlation coefficients were calculated. Outliers were detected using the Grubbs' test and removed from further analyses. A value of $\mathrm{P}<0.05$ was considered statistically significant. The reference ranges of the markers were calculated as the $5^{\text {th }}$ and $95^{\text {th }}$ percentiles.

Multivariate regression was performed on the relationship between salivary and plasma markers, or urinary and plasma markers, using gender as a fixed factor and weight and age as covariates, employing the general linear model (GLM), (SPSS v. 20, SPSS Inc., Chicago, IL, USA).

\section{Results}

TBARS, AOPP, fructosamine, GSH/GSSG ratio, TAC and FRAP were detected in the plasma and urine of the mice. TBARS and the GSH/GSSG ratio, along with the markers of antioxidant status TAC and FRAP, were detected in the saliva of adult healthy mice. Salivary fructosamine concentrations were under the detection limit. Salivary AOPP were not measured. LOD was determined for TBARS to be $0.32 \mu \mathrm{mol} / 1$. For AOPP, LOD was $13.21 \mu \mathrm{mol} / 1$. LOD calculated for fructosamine was $0.72 \mathrm{mmol} / 1$, for $\mathrm{GSH}$, it was $9.46 \mu \mathrm{mol} / 1$, for $\mathrm{GSSG}$, $22.8 \mu \mathrm{mol} / 1$. In case of TAC, LOD was calculated as $8.93 \mu \mathrm{mol} / 1$, and for FRAP, it was $134.35 \mu \mathrm{mol} / 1$. Reference ranges for the measured plasma, urinary and salivary markers were assessed in mice of both sexes. Plasma TBARS were $10 \%$ higher in males $(\mathrm{P}<0.05)$. Plasma fructosamine was higher in females by $15 \%$ $(\mathrm{P}<0.001)$ (Table 1). When sex differences were assessed in urinary markers, urinary TBARS and TAC showed no significant differences between the sexes. Urinary AOPP were higher in females by $207 \% \quad(\mathrm{P}<0.001)$, while urinary fructosamine was higher in males by $108 \%$ $(\mathrm{P}<0.001)$. Urinary GSH/GSSG ratio was higher in males by $201 \%(\mathrm{P}<0.001)$ and urinary FRAP was higher in males by $67 \%(\mathrm{P}<0.001)$. Sex differences in salivary TBARS, TAC, and FRAP, were not significant. Significant sex difference in saliva was observed in the GSH/GSSG ratio, which was higher in females by $55 \%$ $(\mathrm{P}<0.01)$. Salivary TAC was higher in males by $17 \%$ $(\mathrm{P}<0.001)$ (Table 1).

The measured plasma markers did not correlate significantly with the age of the animals (Figs 1A-1F). Urinary TAC negatively correlated with the age of the animals (Fig. 2E; $\mathrm{r}=-0.23, \mathrm{P}<0.05$ ) as did urinary FRAP (Fig. 2F; $\mathrm{r}=-0.05, \mathrm{P}<0.05$ ). Urinary TBARS, AOPP, fructosamine or GSH/GSSG did not correlate with age significantly (Figs 2A-2D). Salivary markers did not significantly correlate with age (Figs 3A-3D).

Plasma fructosamine correlated significantly with weight $(\mathrm{r}=-0.28, \mathrm{P}<0.05)$. Plasma TBARS, AOPP, GSH/GSSG, TAC or FRAP did not correlate with weight significantly (Supplementary Fig. S1). Out of the urinary markers only GSH/GSSG ratio correlated positively with the weight of the animals $(\mathrm{r}=0.39 ; \quad \mathrm{P}<0.001)$ (Supplementary Fig. S2). The measured salivary markers did not correlate with the weight of the animals (Supplementary Fig. S3). Urinary and plasma concentrations did not correlate significantly in any of the measured markers (Figs 4A-4F). Salivary concentrations did not correlate significantly with plasma concentrations either (Figs 5A-5D). GLM analysis confirmed the results of simple regression analyses on the significant sex differences, on the relationship between age, weight and plasma, urinary and salivary markers, and on the absence of significant relationships between urinary and plasma markers or salivary and plasma markers.

Intra-plate variability of TBARS expressed by $\mathrm{CV}$ was $3.26 \%$ in the plate where plasma was assessed, $10.12 \%$ in urine, and $12.75 \%$ in saliva. Inter-plate $\mathrm{CV}$ was $38.59 \%$. In case of AOPP, intra-plate $\mathrm{CV}$ was $8.17 \%$ in plasma, and $6.85 \%$ in urine. Inter-plate $\mathrm{CV}$ was $9.97 \%$. In fructosamine, the $\mathrm{CV}$ of plasma was $7.28 \%$, and of urine, it was $4 \%$. Inter-plate $\mathrm{CV}$ was $14.2 \%$. Intra-plate $\mathrm{CV}$ of GSH was $7.59 \%$ in plasma, $11.8 \%$ in urine, and $12.06 \%$ in saliva. Inter-plate CV was $12.3 \%$. In GSSG, CV was $6.12 \%$ in the plasma plate, $2.45 \%$ in urine, and $9.01 \%$ in saliva. Inter-plate $\mathrm{CV}$ was $7.84 \%$. Intra-plate $\mathrm{CV}$ of TAC was $5.77 \%$ in the plasma plate, $1.27 \%$ in urine, and $4.95 \%$ in saliva. Inter-plate CV was $14.29 \%$. Intra-plate CV of FRAP was $11.79 \%$ in plasma, $1.12 \%$ in urine, and $3.45 \%$ in saliva. Inter-plate CV was calculated as $25.09 \%$. 


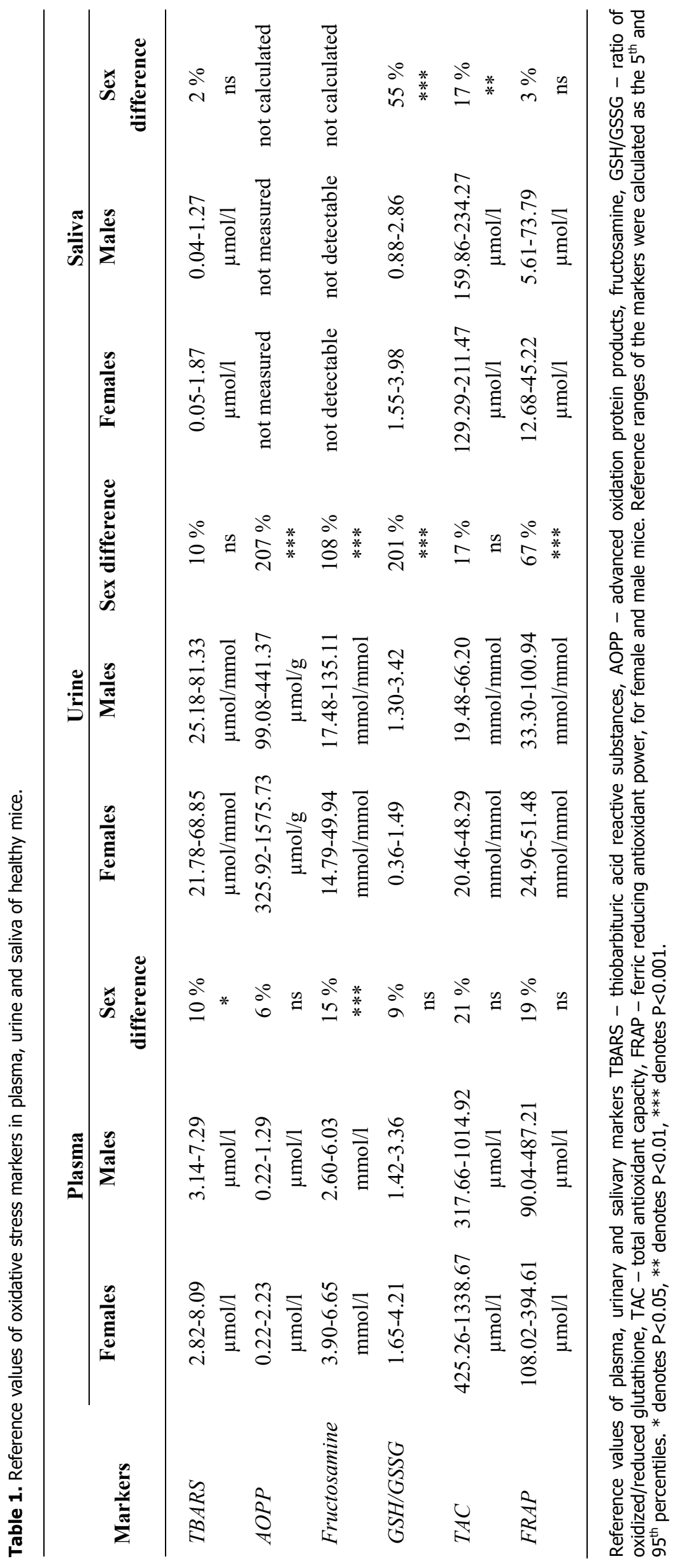


A

TBARS

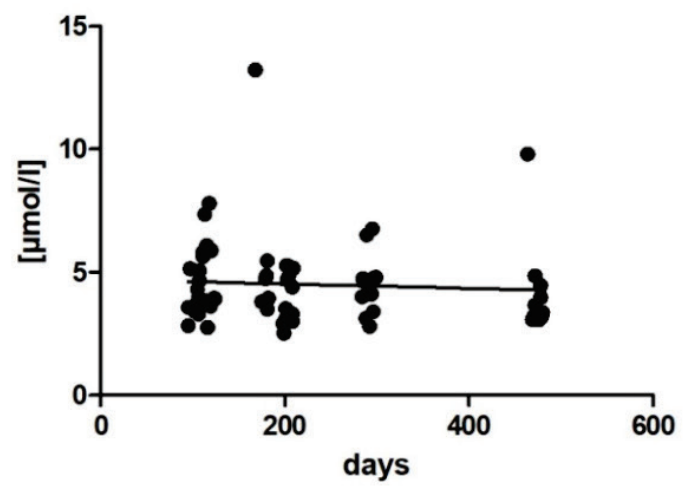

Fructosamine

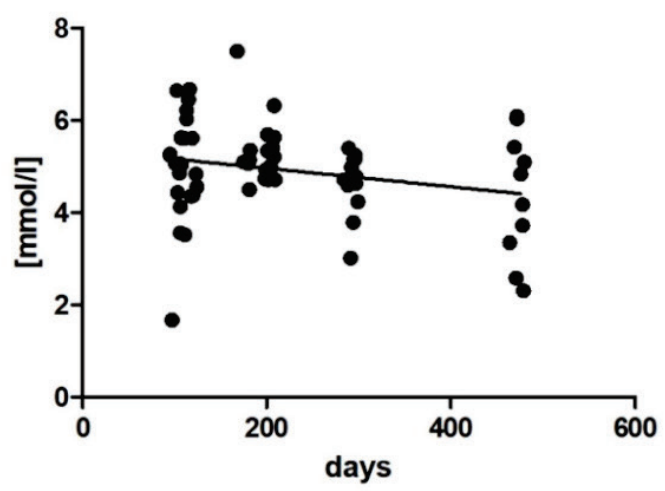

E

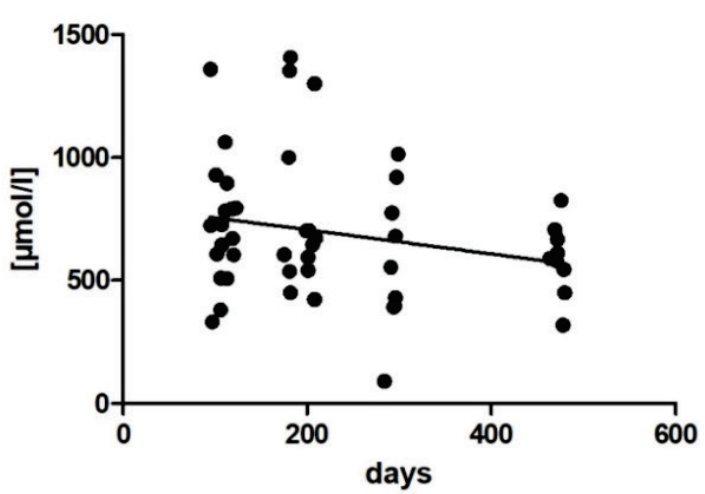

B

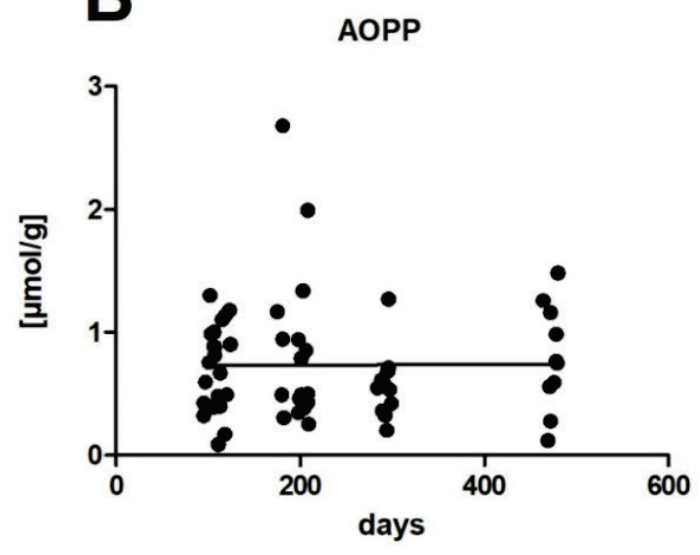

D

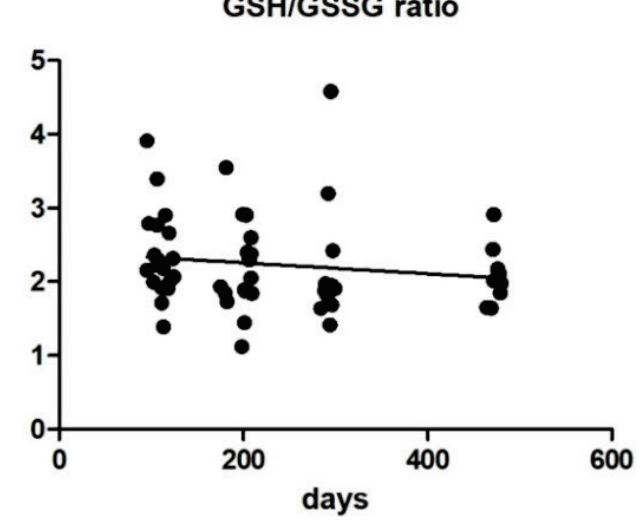

$\mathbf{F}$

FRAP

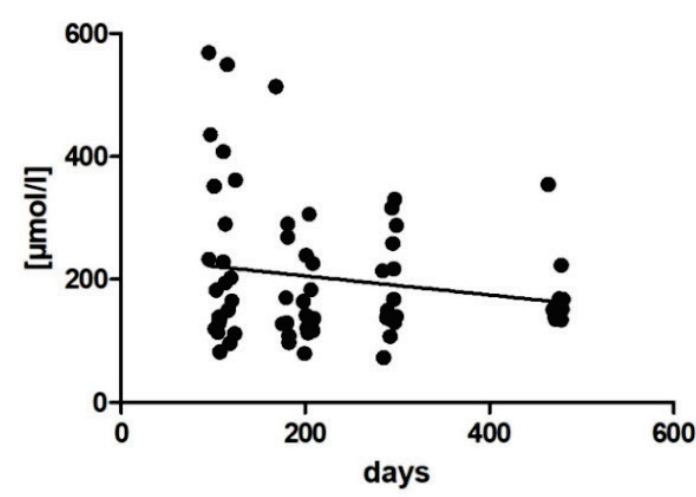

Fig. 1. Correlations between age and plasma (A) TBARS - thiobarbituric acid reactive substances, (B) AOPP - advanced oxidation protein products, (C) fructosamine, (D) GSH/GSSG - ratio of oxidized/reduced glutathione, (E) TAC - total antioxidant capacity, (F) FRAP - ferric reducing antioxidant power.

\section{Discussion}

The main goal of this study was the assessment of reference values of plasma, urinary and salivary biomarkers of oxidative stress in healthy mice and the identification of at least some of the sources of their variability. In plasma, several studies established reference values for some oxidative stress markers including AOPP and isoprostanes in human neonates (Longini et al. 2017) or healthy dogs (Tomsič et al. 2016). According to our knowledge, studies exploring the reference values of oxidative stress markers in these biofluids of healthy laboratory mice have not been published. 


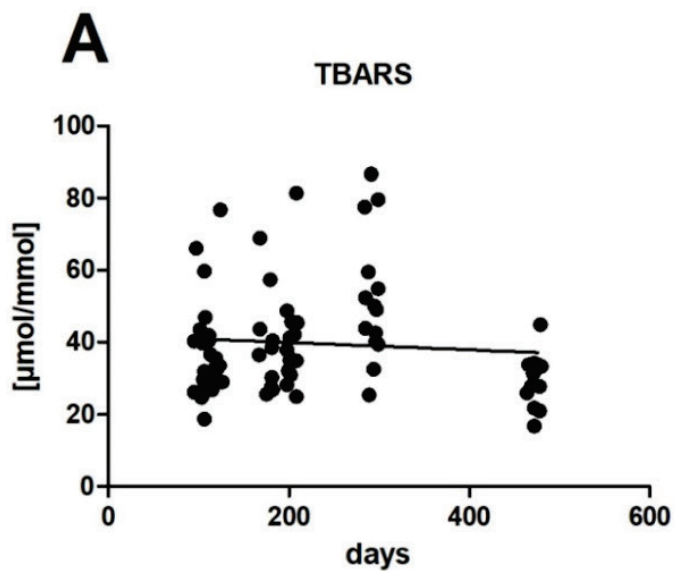

C

Fructosamine

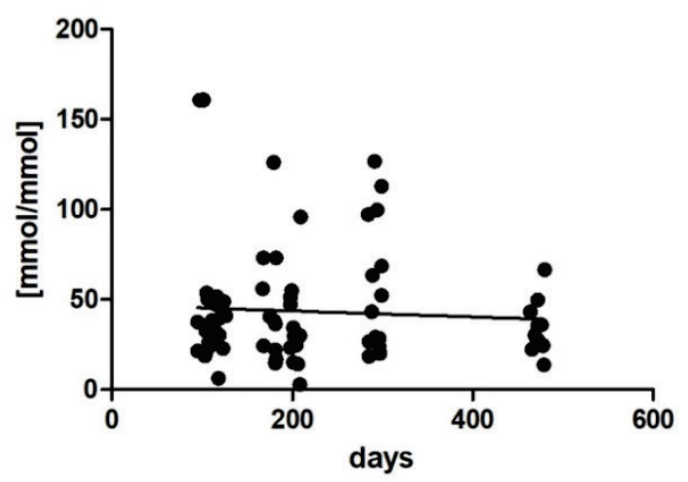

$\mathbf{E}$

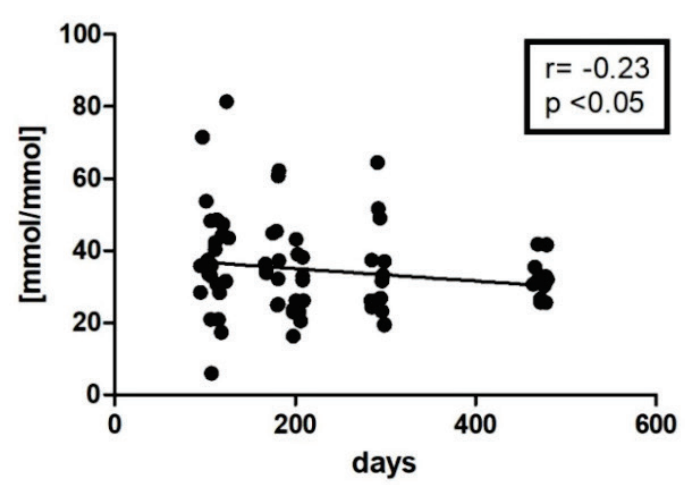

B

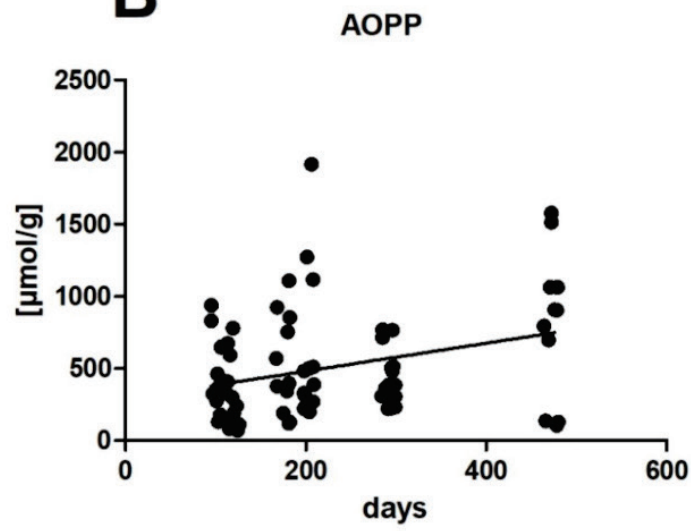

D

GSH/GSSG ratio

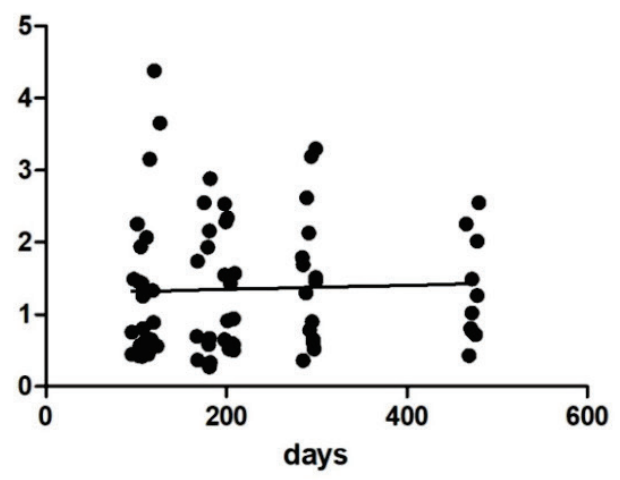

E

FRAP

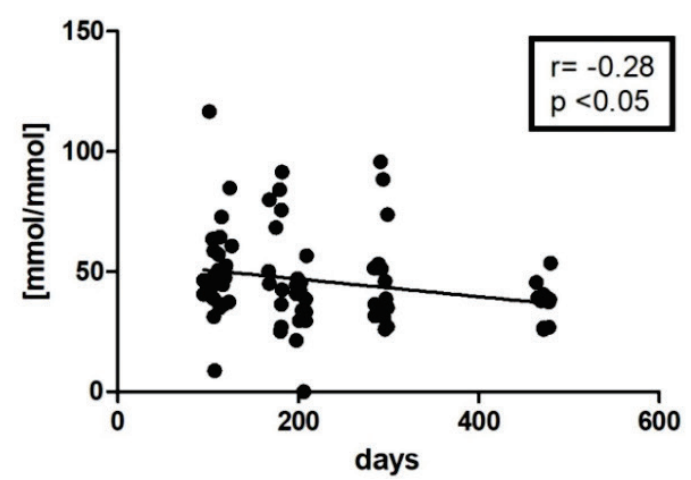

Fig. 2. Correlations between age and urinary (A) TBARS - thiobarbituric acid reactive substances, (B) AOPP - advanced oxidation protein products, (C) fructosamine, (D) GSH/GSSG - ratio of oxidized/reduced glutathione, (E) TAC - total antioxidant capacity, (F) FRAP - ferric reducing antioxidant power. Significant correlations are shown between age and TAC, and between age and FRAP.

Most studies in humans show that females are more protected against oxidative stress compared to males, presumably by the effects of estradiol (Sculley and Langley-Evans 2003, Bloomer and Fisher-Wellman 2008, Bloomer and Fisher-Wellman 2010). Studies assessing the sex differences of oxidative stress markers in biofluids are limited. However, a metabolite of 8 -isoprostaglandin F2 $\alpha$ has been shown to be higher in the urine of females compared to males, and salivary TAC and FRAP to be lower in females (Sculley and Langley-Evans 2003, Il'yasova et al. 2005, Lettrichova et al. 2016). Although the oxidative stress markers are commonly measured in rodents, sex differences and reference values themselves were not described. In our experiment, significant sex differences were shown in plasma TBARS, which was higher in male mice. 


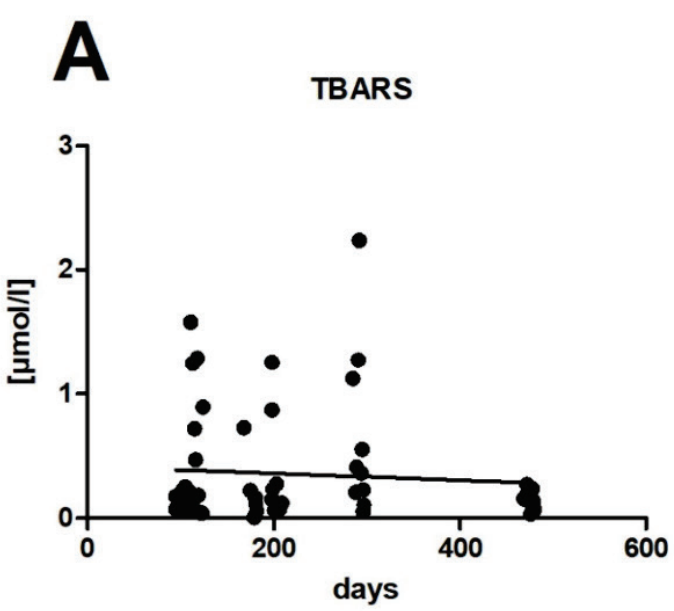

TAC

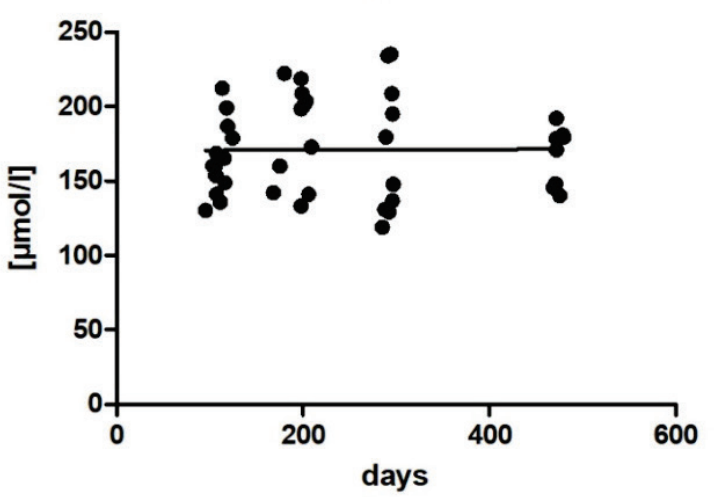

B

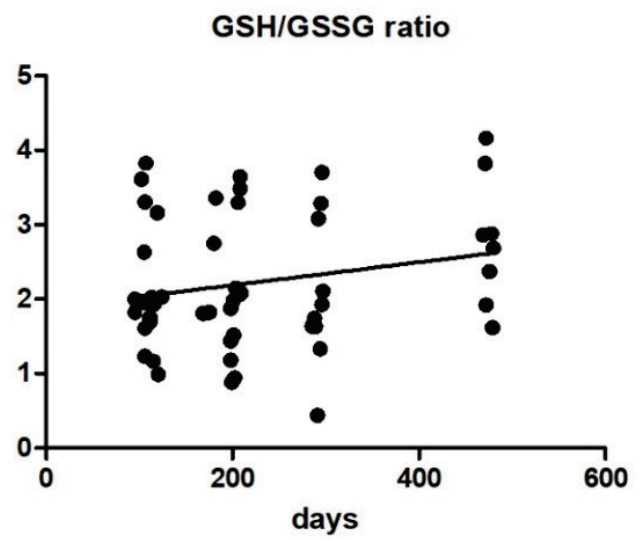

D

FRAP

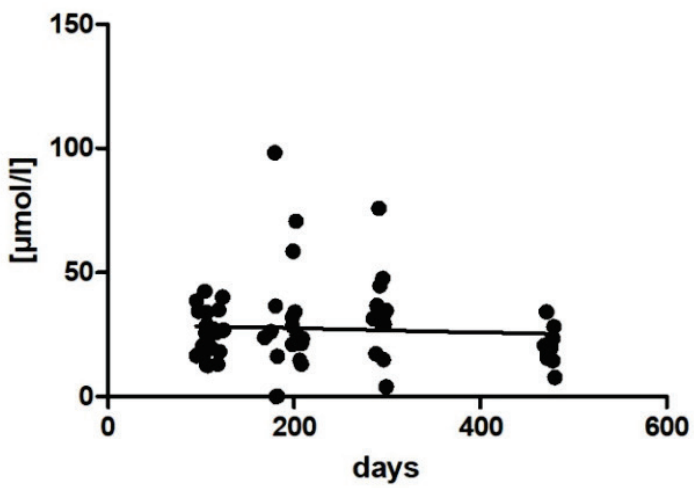

Fig. 3. Correlations between age and salivary (A) TBARS - thiobarbituric acid reactive substances, (B) GSH/GSSG - ratio of oxidized/reduced glutathione, (C) TAC - total antioxidant capacity, (D) FRAP - ferric reducing antioxidant power.

This is in accordance with previous findings in humans (Reckelhoff et al. 2004). Plasma fructosamine, on the contrary, was observed to be higher in female mice. Lower AOPP and higher FRAP and GSH/GSSG ratio were found in the urine of male mice. This could point to a higher antioxidant status of male urine. In saliva, a higher GSH/GSSG ratio was found in female mice, but salivary TAC was higher in male mice, as opposed to human studies. The possible explanation could come from the fact that human studies generally use unstimulated saliva, and the salivary flow has been shown to be lower in females (Inoue et al. 2006). In our study, pilocarpine had to be used to stimulate saliva production, which increases the salivary flow. Therefore, true sex differences observed in humans might be related to sex differences in saliva production and composition.

Aging is causally related to oxidative stress. The free radical theory of aging has been postulated over half a century ago (Harman 1956, Chrysohoou et al. 2007, Fernández-Sánchez et al. 2011, Serra et al. 2013, Savini et al. 2013). It has been shown that in species in which females have a shorter life span than males, females produce more free radicals (Viña et al. 2013). A study has shown that aging mice have higher concentrations of oxidative stress markers and lower antioxidant status in saliva (Yamauchi et al. 2017). The majority of animal experiments are performed using young to middle aged animals. Thus the reference values were described in this age category, rather than in older animals. In the present study, no correlations were found between the concentrations of the measured plasma or salivary markers, and the age of healthy mice. The relatively stable physiology of young to middle aged rodents could explain the lack of association between oxidative stress and aging in our experiment. On the other hand, it has also been observed that aging ( 52 weeks of age) Wistar rats display higher urinary TBARS concentrations than young (13 weeks of age) rats (Gomes et al. 2009). While the present study did not find any correlations between age and urinary oxidative stress markers, it has been found 

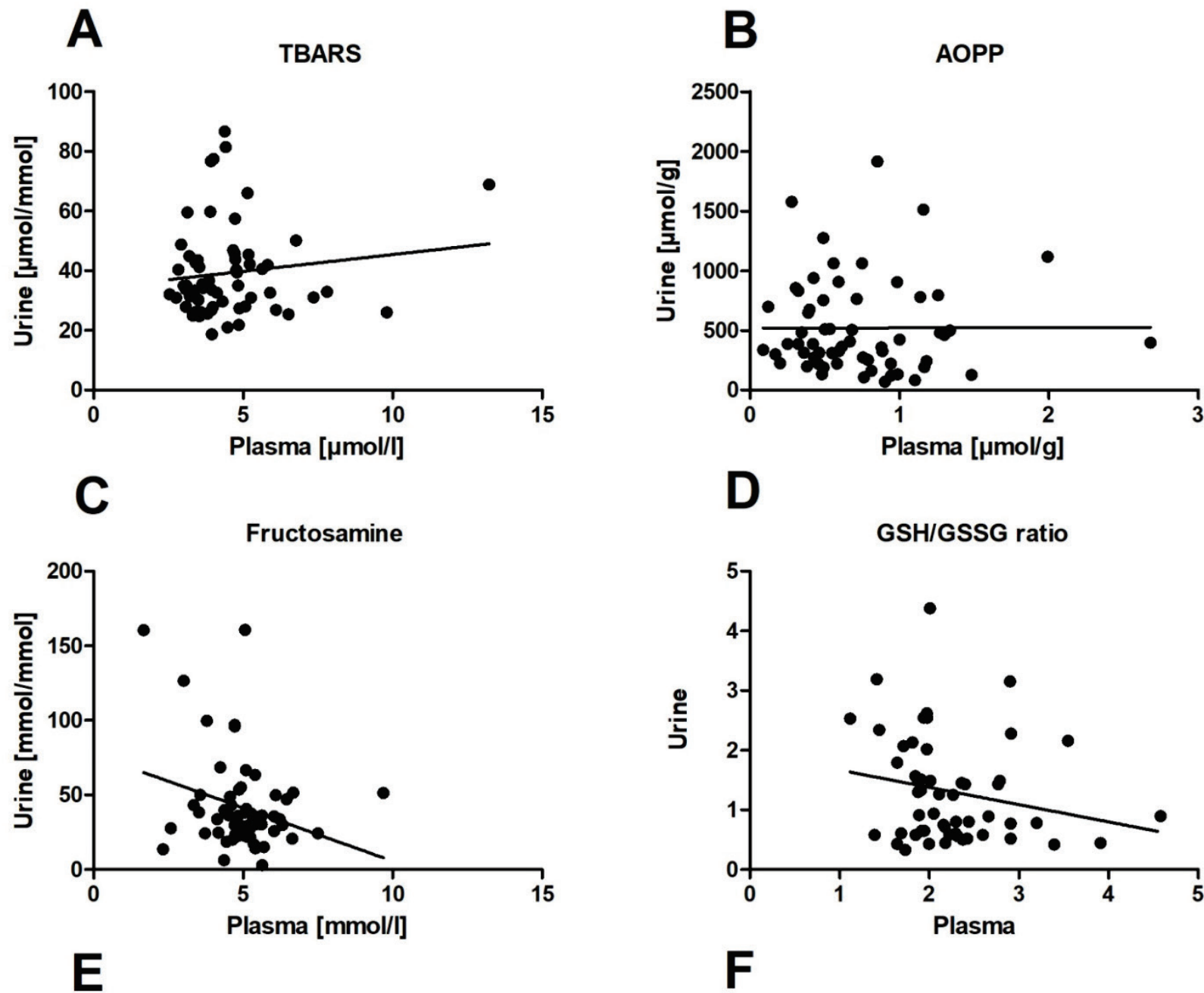

TAC

FRAP
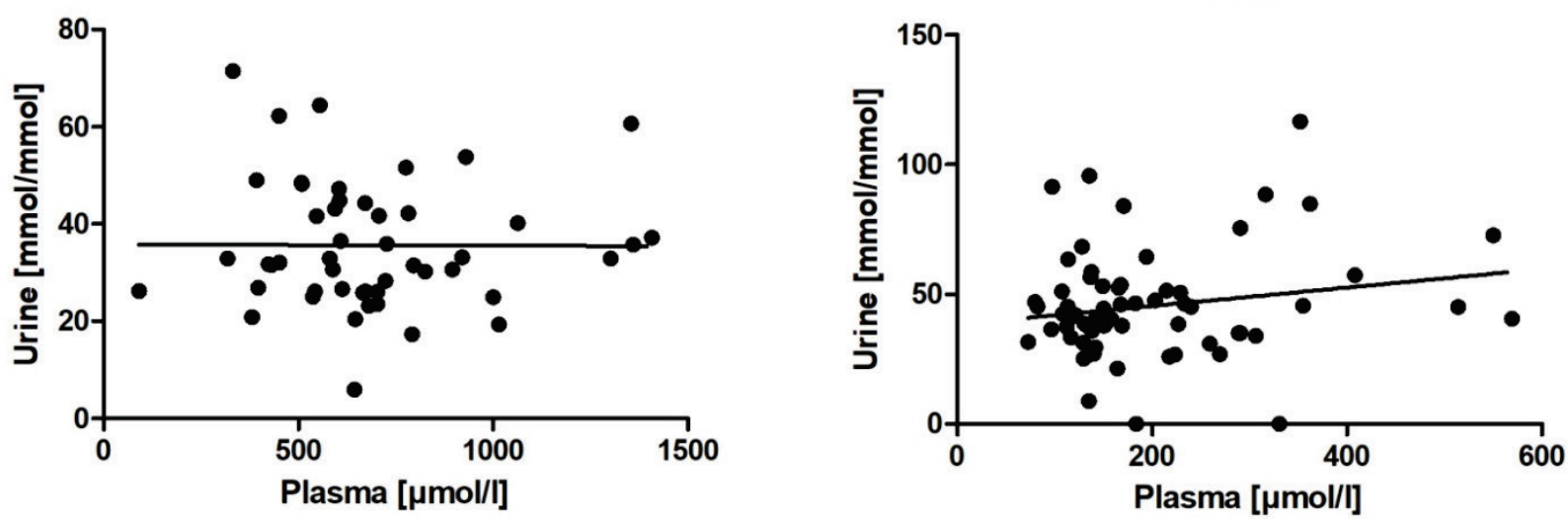

Fig. 4. Correlations between plasma and urinary concentrations of (A) TBARS - thiobarbituric acid reactive substances, (B) AOPP advanced oxidation protein products, (C) fructosamine, (D) GSH/GSSG - ratio of oxidized/reduced glutathione, (E) TAC - total antioxidant capacity, (F) FRAP - ferric reducing antioxidant power.

that urinary TAC and FRAP decrease significantly with age. This could mean that urinary antioxidant status starts to decline in middle age, before changes in plasma antioxidant status manifest.

Systemic oxidative stress can be induced by various states and diseases, of which increased weight and obesity belong to the most elementary. Oxidative stress in overweight and obesity can be triggered via various pathways. For instance, superoxide generation from NADPH oxidases, oxidative phosphorylation, chronic inflammation and low antioxidant status account for some of these pathways (Chrysohoou et al. 2007, 
A

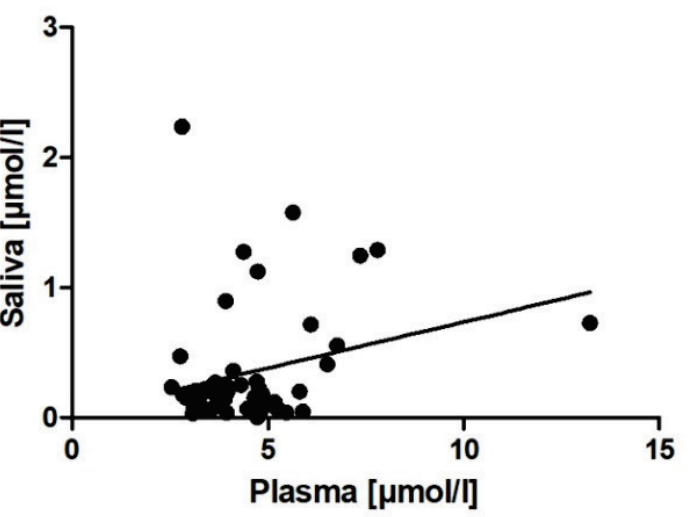

C

TAC

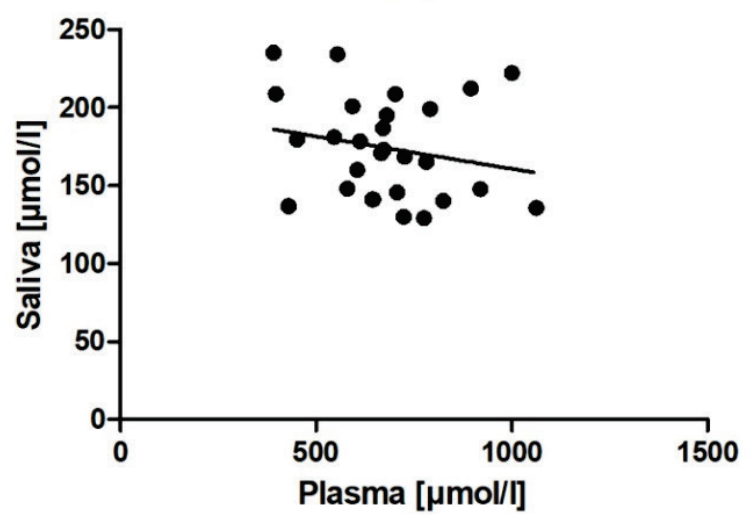

B

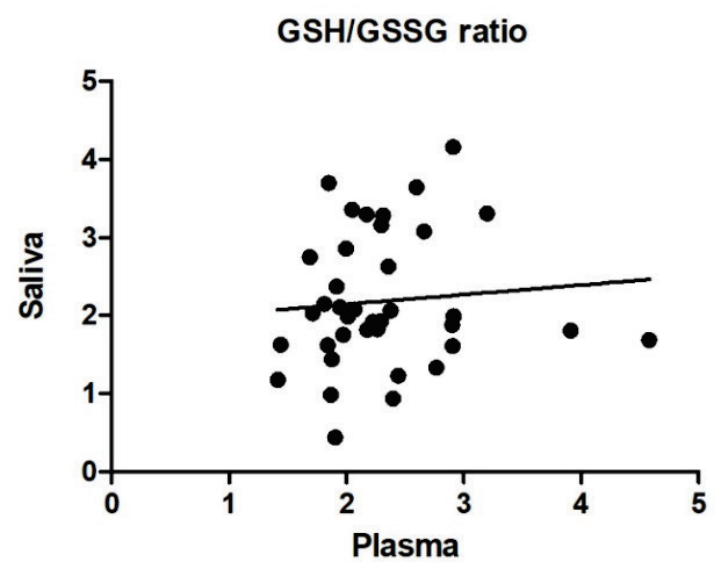

D

FRAP

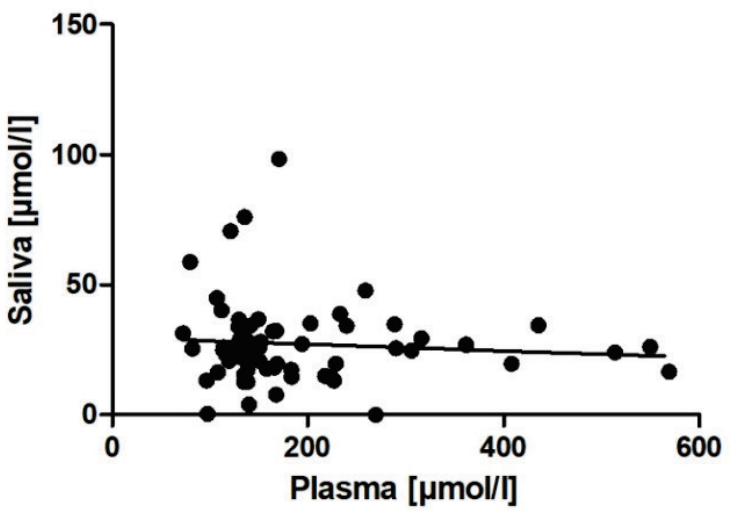

Fig. 5. Correlations between plasma and salivary concentrations of (A) TBARS - thiobarbituric acid reactive substances, (B) GSH/GSSG - ratio of oxidized/reduced glutathione, (C) TAC - total antioxidant capacity, (D) FRAP - ferric reducing antioxidant power.

Fernández-Sánchez et al. 2011, Serra et al. 2013, Savini et al. 2013). In this study, a negative correlation has been found between plasma fructosamine and bodyweight, and no correlations were found between salivary oxidative stress markers and weight. The mice were healthy in our study, despite the variability in bodyweight. Interestingly, it has been postulated, that urinary oxidative stress markers reflect the intensity of oxidative fat metabolism, which can protect against the development of obesity (Zurlo et al. 1990, Seidell et al. 1992, Valtueña et al. 1997, Marra et al. 2004, Il'yasova et al. 2005). This is reflected in the results of the present study, since a positive correlation between weight and urinary GSH/GSSG ratio has been found.

Urinary oxidative stress markers can reflect local and systemic changes of oxidative status. Nevertheless, these differ within various systemic disorders (Kirschbaum 2001). In the present study, where healthy mice were examined, no correlations between urinary and plasma TBARS, AOPP, fructosamine, GSH/GSSG, TAC or FRAP concentrations were found. The absence of correlations between plasma and urinary oxidative stress markers suggests that urinary oxidative stress markers mirrors local oxidative status of healthy kidneys in the mice. Similarly, no correlations between salivary and plasma TBARS, GSH/GSSG, TAC or FRAP concentrations were found. In human studies, a variety of biomarkers have been shown to correlate between individual biofluids, such as plasma, urine and saliva suggesting that the analysis of these in alternative biofluids could be helpful in the evaluation of systemic status. For example, a positive correlation between salivary and plasma concentrations of FRAP was described in young athletes. Moreover, a positive correlation of salivary and plasma GSH concentrations has been shown in periodontitis patients as well as 
healthy controls (Lyszczarz et al. 2002, Öngöz Dede et al. 2016). On the other hand, in patients with inflammatory periodontal disease, salivary TBARS has not been shown to correlate with plasma TBARS, which could mean that even a major local process does not necessarily reflect in systemic oxidative stress parameters (Celec et al. 2005, Iannitti et al. 2012). The discrepancies between our animal experiment and other human studies cannot be further explained as of now, since animal experiments related to this topic are simply missing.

During our experiment, several limitations emerged. It should be mentioned that saliva collection from mice without stimulation would produce unusable amounts. Stimulation by pilocarpine greatly increased salivary flow, but it still did not reach the optimal volume for analysis. Additionally, the stimulated flow probably influenced the composition of saliva, diminishing the sex differences or plasma:saliva correlations. It should also be mentioned that pilocarpine has been shown to induce oxidative stress in the rodent brain, although such an effect has not been studied in body fluids yet (Freitas et al. 2005). Salivary AOPP could not be measured, since $200 \mu \mathrm{l}$ of undiluted saliva are needed for this assay. Even by stimulation, only around $400 \mu \mathrm{l}$ of saliva were collected. Thus, most of the samples were used up for the measurement of other markers. Samples were not pooled, which could have solved the issue of low sample volume. Fructosamine was under the limit of detection when measured in saliva samples. However, fructosamine concentrations are under the limit of detection in human saliva as well, by using this spectrophotometric method. On the other hand, in urine, both of these markers were measurable.

In human studies, the normalization of salivary markers is still an unsolved question. Saliva flow rate, protein and creatinine concentrations have all been proposed for normalization. In this study, only urinary oxidative markers were normalized, to creatinine, except for AOPP, which was normalized to protein concentrations. Urine was only collected for $4 \mathrm{~h}$ during daytime, and the daily diuresis of the mice was calculated based on the volume produced during this period. Thus, the possible circadian rhythm of urine production was omitted.

The volatile anesthesia used for blood collection could also have influenced the measured oxidative stress markers, however, the body of literature on anesthetics and oxidative stress is quite ambivalent. It has been found that isoflurane increases DNA damage by oxidative stress, but volatile anesthetics like isoflurane or sevoflurane have been found to reduce oxidative stress and inflammation in rodents (Lee et al. 2015, Ni et al. 2017). One study showed that inhalational anesthetics can induce oxidative stress to some extent, by acting against antioxidant defense systems (Ruxanda et al. 2015). Injectable anesthetics, such as ketamine, have been proposed to increase oxidative stress in rodent brains, but other studies describe their antioxidant properties (De Oliveira et al. 2009, Gokcinar et al. 2013). Moreover, during the measurement of TBARS, no antioxidant was added to the samples before heating. Thus, new, heat induced lipid peroxidation products could have formed.

In conclusion, the present study assessed the physiological values of oxidative stress and antioxidant status markers in the plasma, urine and saliva of healthy young to middle-aged mice. High inter-individual variability is currently a problem leading to minimal clinical use of urinary and salivary biomarkers. The results of saliva and urine analysis are unreliable, since many known (food, tooth-brushing, smoking, etc.), and unknown factors influence individual biomarker concentrations in alternative biofluids. Animal experiments under controlled conditions eliminate this bias and are therefore necessary. The current study proved that urine and saliva could be obtained in sufficient amounts even from small laboratory animals. The markers of oxidative status can be reliably measured in all examined biofluids. Although some of the between subject variability has been explained, other major sources of biological inconsistency are to be uncovered. Further studies should analyze the correlations in animal models of oxidative stress related diseases, to find out if urinary and salivary oxidative stress markers mirror systemic changes of oxidative stress.

\section{Conflict of Interest}

There is no conflict of interest.

\section{Acknowledgements}

This study was supported by the grant of Comenius University UK/255/2017 and by the Grant Agency of Ministry of Education, Science, Research and Sport of the Slovak Republic VEGA 1/0234/18. 


\section{References}

ASKENAZI DJ, MOORE JF, FINEBERG N, KORALKAR R, CLEVENGER S, SHARER JD: Comparison of methods, storage conditions, and time to analysis of serum and urine creatinine measured from microsamples by liquid chromatography mass spectrometery (LC/MS) vs. Jaffe. J Clin Lab Anal 28: 405-408, 2014.

BARGNOUX A-S, MORENA M, BADIOU S, DUPUY A-M, CANAUD B, CRISTOL J-P; GROUPE DE TRAVAIL DE LA SFBC "BIOLOGIE DES FONCTIONS RENALES ET DE L'INSUFFISANCE RENALE": Carbonyl stress and oxidatively modified proteins in chronic renal failure (in French). Ann Biol Clin (Paris) 67: 153-158, 2009.

BEHULIAK M, PÁLFFY R, GARDLÍK R, HODOSY J, HALCÁK L, CELEC P: Variability of thiobarbituric acid reacting substances in saliva. Dis Markers 26: 49-53, 2009.

BENZIE IF, STRAIN JJ: The ferric reducing ability of plasma (FRAP) as a measure of 'antioxidant power': the FRAP assay. Anal Biochem 239: 70-76, 1996.

BLOOMER RJ, FISHER-WELLMAN KH: Blood oxidative stress biomarkers: influence of sex, exercise training status, and dietary intake. Gend Med 5: 218-228, 2008.

BLOOMER RJ, FISHER-WELLMAN KH: Lower postprandial oxidative stress in women compared with men. Gend Med 7: 340-349, 2010.

CAPEILLÈRE-BLANDIN C, GAUSSON V, DESCAMPS-LATSCHA B, WITKO-SARSAT V: Biochemical and spectrophotometric significance of advanced oxidized protein products. Biochim Biophys Acta - Mol Basis Dis 1689: 91-102, 2004.

CELEC P, HODOSY J, CELECOVÁ V, VODRÁŽKA J, ČERVENKA T, HALČÁK L, BOŽEK P, KOPÁNI M, KÚDELA M: Salivary thiobarbituric acid reacting substances and malondialdehyde - their relationship to reported smoking and to parodontal status described by the papillary bleeding index. Dis Markers 21: 133-137, 2005.

CHRYSOHOOU C, PANAGIOTAKOS DB, PITSAVOS C, SKOUMAS I, PAPADEMETRIOU L, ECONOMOU M, STEFANADIS C: The implication of obesity on total antioxidant capacity in apparently healthy men and women: the ATTICA study. Nutr Metab Cardiovasc Dis 17: 590-597, 2007.

ČOLAK E: New markers of oxidative damage to macromolecules. J Med Biochem 27: 1-16, 2008.

DE OLIVEIRA L, MARLY C, SPIAZZI S, BORTOLIN T, CANEVER L, PETRONILHO F, MINA FG, DAL-PIZZOL F, QUEVEDO J, ZUGNO AI: Different sub-anesthetic doses of ketamine increase oxidative stress in the brain of rats. Prog Neuropsychopharmacol Biol Psychiatry 33: 1003-1008, 2009.

EREL O: A novel automated direct measurement method for total antioxidant capacity using a new generation, more stable ABTS radical cation. Clin Biochem 37: 277-285, 2004.

FERNÁNDEZ-SÁNCHEZ A, MADRIGAL-SANTILLÁN E, BAUTISTA M, ESQUIVEL-SOTO J, MORALESGONZÁLEZ A, ESQUIVEL-CHIRINO C, DURANTE-MONTIEL I, SÁNCHEZ-RIVERA G, VALADEZVEGA C, MORALES-GONZÁLEZ JA: Inflammation, oxidative stress, and obesity. Int $J$ Mol Sci 12: 3117-3132, 2011.

FREITAS RM, VASCONCELOS SMM, SOUZA FCF, VIANA GSB, FONTELES MMF: Oxidative stress in the hippocampus after pilocarpine-induced status epilepticus in Wistar rats. FEBS J 272: 1307-1312, 2005.

FRIJHOFF J, WINYARD PG, ZARKOVIC N, DAVIES SS, STOCKER R, CHENG D, KNIGHT AR, TAYLOR EL, OETTRICH J, RUSKOVSKA T, GASPAROVIC AC, CUADRADO A, WEBER D, POULSEN HE, GRUNE T, SCHMIDT HHHW, GHEZZI P: Clinical relevance of biomarkers of oxidative stress. Antioxid Redox Signal 23: 1144-1170, 2015.

GOKCINAR D, ERGIN V, CUMAOGLU A, MENEVSE A, ARICIOGLU A: Effects of ketamine, propofol, and ketofol on proinflammatory cytokines and markers of oxidative stress in a rat model of endotoxemia-induced acute lung injury. Acta Biochim Pol 60: 451-456, 2013.

GOMES P, SIMÃO S, SILVA E, PINTO V, AMARAL JS, AFONSO J, SERRÃO MP, PINHO MJ, SOARES-DASILVA P: Aging increases oxidative stress and renal expression of oxidant and antioxidant enzymes that are associated with an increased trend in systolic blood pressure. Oxid Med Cell Longev 2: 138-145, 2009.

HARMAN D: Aging: a theory based on free radical and radiation chemistry. J Gerontol 11: 298-300, 1956. 
IANNITTI T, ROTTIGNI V, PALMIERI B: Role of free radicals and antioxidant defences in oral cavity-related pathologies. J Oral Pathol Med 41: 649-661, 2012.

IL'YASOVA D, MORROW JD, WAGENKNECHT LE: Urinary $\mathrm{F}_{2}$-isoprostanes are not associated with increased risk of type 2 diabetes. Obes Res 13: 1638-1644, 2005.

IL'YASOVA D, SCARBROUGH P, SPASOJEVIC I: Urinary biomarkers of oxidative status. Clin Chim Acta 413: 1446-1453, 2012.

INOUE H, ONO K, MASUDA W, MORIMOTO Y, TANAKA T, YOKOTA M, INENAGA K: Gender difference in unstimulated whole saliva flow rate and salivary gland sizes. Arch Oral Biol 51: 1055-1060, 2006.

KAMODYOVÁ N, TÓTHOVÁ L, CELEC P: Salivary markers of oxidative stress and antioxidant status: influence of external factors. Dis Markers 34: 313-321, 2013.

KIRSCHBAUM B: Total urine antioxidant capacity. Clin Chim Acta 305: 167-173, 2001.

KISHABONGO AS, KATCHUNGA P, VAN AKEN EH, SPEECKAERT R, LAGNIAU S, COOPMAN R, SPEECKAERT MM, DELANGHE JR: Glycation of nail proteins: from basic biochemical findings to a representative marker for diabetic glycation-associated target organ damage. PLoS One 10: e0120112, 2015.

LEE Y-H, WONG DT: Saliva: an emerging biofluid for early detection of diseases. Am J Dent 22: 241-248, 2009.

LEE Y-M, SONG BC, YEUM K-J: Impact of volatile anesthetics on oxidative stress and inflammation. Biomed Res Int 2015: 242709, 2015.

LETTRICHOVA I, TOTHOVA L, HODOSY J, BEHULIAK M, CELEC P: Variability of salivary markers of oxidative stress and antioxidant status in young healthy individuals. Redox Rep 21: 24-30, 2016.

LONGINI M, BELVISI E, PROIETTI F, BAZZINI F, BUONOCORE G, PERRONE S: Oxidative stress biomarkers: establishment of reference values for isoprostanes, AOPP, and NPBI in cord blood. Mediators Inflamm 2017: $1758432,2017$.

LYSZCZARZ R, STYPUŁKOWSKA J, STEPNIEWSKI M, SZOT WM: Evaluation of saliva antioxidant activity for determining the state of dentition and oral hygiene in a group of young athletes (in Polish). Wiad Lek $\mathbf{5 5}$ (Suppl 1): 768-772, 2002.

MARRA M, SCALFI L, CONTALDO F, PASANISI F: Fasting respiratory quotient as a predictor of long-term weight changes in non-obese women. Ann Nutr Metab 48: 189-192, 2004.

NI C, LI C, DONG Y, GUO X, ZHANG Y, XIE Z: Anesthetic isoflurane induces DNA damage through oxidative stress and p53 pathway. Mol Neurobiol 54: 3591-3605, 2017.

ÖNGÖZ DEDE F, BOZKURT DOĞAN Ş, BALLI U, AVCI B, DURMUŞLAR MC, BARATZADE T: Glutathione levels in plasma, saliva and gingival crevicular fluid after periodontal therapy in obese and normal weight individuals. J Periodontal Res 51: 726-734, 2016.

RECKELHOFF JF, FORTEPIANI LA, YANES LL, CUCCHIARELLI VE: Sex differences in hypertension and renal injury. Adv Mol Cell Biol 34: 167-182, 2004.

RUXANDA F, MICLAUS V, RUS V, GAL AF, OANA L: Oxidative stress evaluation in rats anesthetized with isoflurane or sevoflurane. Bull Univ Agric Sci Vet Med Cluj-Napoca Vet Med 72: 181-182, 2015.

SAVINI I, CATANI MV, EVANGELISTA D, GASPERI V, AVIGLIANO L: Obesity-associated oxidative stress: strategies finalized to improve redox state. Int J Mol Sci 14: 10497-10538, 2013.

SCULLEY D V, LANGLEY-EVANS SC: Periodontal disease is associated with lower antioxidant capacity in whole saliva and evidence of increased protein oxidation. Clin Sci 105: 167-172, 2003.

SEIDELL JC, MULLER DC, SORKIN JD, ANDRES R: Fasting respiratory exchange ratio and resting metabolic rate as predictors of weight gain: the Baltimore Longitudinal Study on Aging. Int J Obes Relat Metab Disord 16: 667-674, 1992.

SERRA D, MERA P, MALANDRINO MI, MIR JF, HERRERO L: Mitochondrial fatty acid oxidation in obesity. Antioxid Redox Signal 19: 269-284, 2013.

SIES H: Oxidative stress: oxidants and antioxidants. Exp Physiol 82: 291-295, 1997.

TOMSIČ K, SELIŠKAR A, LUKANC B, NEMEC SVETE A: Plasma total antioxidant capacity and activities of blood glutathione peroxidase and superoxide dismutase determined in healthy dogs by using commercially available kits. Acta Vet Brno 66: 534-548, 2016. 
TÓTHOVÁ L, HODOSY J, METTENBURG K, FÁBRYOVÁ H, WAGNEROVÁ A, BÁBÍČKOVÁ J, OKULIAROVÁ M, ZEMAN M, CELEC P: No harmful effect of different Coca-cola beverages after 6 months of intake on rat testes. Food Chem Toxicol 62: 343-348, 2013.

TÓTHOVÁ L, KAMODYOVÁ N, ČERVENKA T, CELEC P: Salivary markers of oxidative stress in oral diseases. Front Cell Infect Microbiol 5: 73, 2015.

VALKO M, LEIBFRITZ D, MONCOL J, CRONIN MTD, MAZUR M, TELSER J: Free radicals and antioxidants in normal physiological functions and human disease. Int J Biochem Cell Biol 39: 44-84, 2007.

VALTUEÑA S, SALAS-SALVADÓ J, LORDA PG: The respiratory quotient as a prognostic factor in weight-loss rebound. Int J Obes Relat Metab Disord 21: 811-817, 1997.

VIÑA J, BORRAS C, ABDELAZIZ KM, GARCIA-VALLES R, GOMEZ-CABRERA MC: The free radical theory of aging revisited: the cell signaling disruption theory of aging. Antioxid Redox Signal 19: 779-787, 2013.

YAMAUCHI Y, MATSUNO T, OMATA K, SATOH T: Relationship between hyposalivation and oxidative stress in aging mice. J Clin Biochem Nutr 61: 40-46, 2017.

ZITKA O, SKALICKOVA S, GUMULEC J, MASARIK M, ADAM V, HUBALEK J, TRNKOVA L, KRUSEOVA J, ECKSCHLAGER T, KIZEK R: Redox status expressed as GSH:GSSG ratio as a marker for oxidative stress in paediatric tumour patients. Oncol Lett 4: 1247-1253, 2012.

ZURLO F, LILLIOJA S, ESPOSITO-DEL PUENTE A, NYOMBA BL, RAZ I, SAAD MF, SWINBURN BA, KNOWLER WC, BOGARDUS C, RAVUSSIN E: Low ratio of fat to carbohydrate oxidation as predictor of weight gain: study of 24-h RQ. Am J Physiol 259: E650-E657, 1990. 